TRIBUNAL CONSTITUCIONAL 



\title{
IL TEMPO MODERATO DE LA INTERVENCIÓN COERCITIVA DEL ESTADO (ARTÍCULO155 CE) EN CATALUÑA: UN COMENTARIO A LAS SSTC 89 Y 90/2019, EN PARTICULAR, PROPORCIONALIDAD Y TEST DE NECESIDAD O RAZONABILIDAD DE LAS MEDIDAS.
}

\author{
JAVIER GARCÍA ROCA \\ Catedrático de Derecho Constitucional \\ Universidad Complutense de Madrid
}

\section{SUMARIO}

I. Objeto y propósito. II. Un tempo moderato en la ejecución del artículo 155 CE y en su exégesis. III. Principales contenidos de la STC 89/2019. IV. La STC 90/2019. V. Algunas cuestiones a disputar: la exclusión del juicio de necesidad y proporcionalidad, y la revisión de las disposiciones y actos en desarrollo del Acuerdo del Senado. VI. A modo de conclusión.

\section{OBJETO Y PROPÓSITO}

Me propongo comentar las SSTC 89 y 90/2019, de 2 de julio, que resuelven los recursos de inconstitucionalidad presentados, respectivamente, por cincuenta Diputados del Grupo parlamentario de Unidos-Podemos-En Comú Podem, y por el Parlamento de Cataluña frente al Acuerdo del Pleno Senado, de 27 de octubre de 2017, por el que se aprueban las medidas adoptadas por el Gobierno al amparo del artículo $155 \mathrm{CE}$ y las disposiciones dictadas en desarrollo del mismo. La Magistrada ponente de la primera fue E. Roca y P. González-Trevijano el de la segunda. El Tribunal Constitucional decidió no acumular ambos recursos, y los fundamentos de la última reproducen las tesis de la primera.

El comentario servirá también para dar noticia de un importante libro, de próxima edición por el Centro de Estudios Políticos y Constitucionales, que recoge las «Actas de las XXIV Jornadas de la Asociación de Letrados del TC» bajo el título «El artículo 155 de la Constitución». Se encomendaron ponencias a varios 
profesores (T. Freixes, J. Vintró, J. García Torres y yo mismo) quienes desde diversas posiciones y aproximaciones, pero todos ellos in extenso, reflexionaron sobre esta primera intervención coercitiva del Estado, mostrando algunas disidencias y bastantes coincidencias. Los escritos fueron redactados tras los sucesos de septiembre y octubre de 2017 en Cataluña y a la vista del primer uso del artículo 155 CE. Dieron lugar a un rico debate en esta asociación de referencia, integrada por expertos en justicia constitucional, en noviembre de 2018. Son pues anteriores a las sentencias de julio de 2019, recogen mucha información y referencias comparadas y doctrinales, no están contaminados por las mismas y de ahí su valor, si doctrina científica y resoluciones judiciales se interrelacionan. Una labor que sugiero, pero apenas puedo esbozar aquí.

En efecto, me parece que aunando la jurisprudencia que se recoge en estas dos sentencias, los cuatro trabajos que menciono y aparecen en un único libro, y otros estudios doctrinales previos que en el libro se citan tenemos ya una documentación bastante completa sobre la intervención estatal ex artículo 155 CE, que permite interpretar el precepto con mucha mayor seguridad, disipando muchas dudas. Algunas otras, como veremos, subsisten.

La grave crisis constitucional en Cataluña que dio lugar a su primera aplicación al menos ha servido para precisar los contornos de este control extraordinario sobre los órganos de las CCAA, aunque dista de haber pacificado el conflicto político. El artículo $155 \mathrm{CE}$ carece de una eficacia taumatúrgica y la jurisdicción constitucional difícilmente puede pacificar emergencias de esa entidad. El Derecho de excepción no puede sustituir a la política constitucional: a la construcción y divulgación de una narrativa española en Cataluña, una propuesta atractiva, para buena parte de los catalanes, por parte de quienes respetan la Constitución y nuestra configuración histórica plural. La inacción no arreglará el problema. Son precisos pactos de Estado cuando menos entre los partidos constitucionales.

Debemos, no obstante, ser prudentes porque podría producirse otra aplicación — esperemos que no sea necesaria - con perfiles distintos a la acaecida, si el supuesto de hecho habilitante se produjera de nuevo. Por si el caso llegara, la jurisprudencia constitucional que reseño ya ha decantado claros límites que deberían ser respetados.

\section{UN TEMPO MODERATO EN LA EJECUCIÓN DEL ARTÍCULO 155 CE Y EN SU EXÉGESIS}

Recuerdo haber escuchado a la Magistrada ponente, E. Roca, una interesante conferencia en la Facultad de Derecho de la Complutense en la cual hizo una analogía entre la interpretación de un texto jurídico y la de una partitura musical. Ambas exégesis tienen un margen de indeterminación y a menudo un carácter constructivo del resultado, dan un estilo a la pieza a la hora de ejecutarla que queda en manos del intérprete. No todas las interpretaciones suenan igual. 
Me parece que tanto la aplicación del artículo 155 CE por el Gobierno del Presidente Rajoy en Cataluña como la lectura que hacen estas sentencias constitucionales de este inexplorado - hasta entonces - mecanismo constitucional tienen un sabio aire moderado. Sabido es que estas viejas indicaciones de tiempo, antes de poder medirse la velocidad con exactitud matemática, adolecen de cierta ambigüedad, pero para la mayoría la que uso indica una velocidad intermedia entre un andante y un allegretto y un cierto estilo contenido en la ejecución de la pieza. Habría quizás cabido una coerción más radical en Cataluña como algunos pretenden, ubicada en una peligrosa frontera de constitucionalidad a la vista de estas sentencias ${ }^{1}$. Aunque la que se siguió no fue pequeña a la vista de medidas tan intensas como son el cese del Presidente y el resto del Gobierno y la disolución del Parlamento de Cataluña, o la intervención de la Administración autonómica. Pero cabrían asimismo al amparo del mismo precepto constitucional otras intervenciones mínimas, si simplemente se produjera el incumplimiento de algunas obligaciones constitucionales y legales y no un grave atentado al interés general de España. El artículo $155 \mathrm{CE}$ ampara adoptar toda una escala de medidas adecuadas al supuesto de hecho habilitante según aclaran estas sentencias.

Los hechos de septiembre y octubre de 2017 constituyeron, pese a venir deliberadamente embozados en algunas calculadas ambigüedades por sus autores lo que estimo les priva de toda grandeza revolucionaria ante la historia-, un irresponsable intento de «destrucción de la Constitución», en los términos clásicos de Carl Schmitt, y del Estatuto de Autonomía y el autogobierno. Se trataba de desplazar la Constitución y sustituir el poder constituyente español por otro distinto, atropellando los derechos políticos de las amplias minorías en Cataluña. Es difícil imaginar unas actuaciones que entrañen un atentado más grave en un Estado de Derecho.

Pero una misma pieza puede interpretarse de varias maneras. La forma que el interprete supremo de la Constitución ha elegido ahora, de forma cabal, al revisar la obra del Gobierno y el Senado, queda consagrada en nuestro ordenamiento jurídico por la eficacia vinculante de sus sentencias. Los partidos políticos deberían acomodarse a este entendimiento, moderando algunas invocaciones retóricas o electoralistas del artículo $155 \mathrm{CE}$, que se ha convertido lamentablemente en el precepto más citado de toda la Constitución, y probablemente dedicar su tiempo a gestionar acuerdos de Estados estables para solventar pacientemente la crisis.

1 T. Freixes, por ejemplo, sostiene que la intervención del Estado en Cataluña no incidió en absoluto en los dos grandes ejes del secesionismo, la educación y la comunicación, y estima que el artículo 155 CE permite muchas más cosas que éstas que se han hecho: una estrategia dirigida a las llamadas «estructuras de Estado» (p. 45). Véase «El artículo 155 de la Constitución y su aplicación en Cataluña» VVAA, El artículo 155 de la Constitución, XXIV Actas de la Asociación de Letrados del TC, CEPC, Madrid, 2019, pp. 13-52, de próxima edición. A mi entender, el Estado podría intervenir y frenar algunos excesos en materia de educación y medios de comunicación públicos, pero no mediante el medio de control excepcional sobre los órganos autonómicos e intervención coercitiva que es el artículo 155 CE sino mediante el ordinario ejercicio de las competencias estatales básicas en materia de educación y régimen de radio y televisión. 


\section{PRINCIPALES CONTENIDOS DE LA STC 89/2019}

La sentencia inicia cada uno de sus fundamentos con un título o descriptor, una buena técnica jurisprudencial que facilita su lectura. Es un pronunciamiento claro, ordenado, distanciado y escrito sin ira y con autoridad. La mayoría de sus razonamientos me parece que pueden ser fácilmente aceptados, si bien abriré alguna pequeña matización más adelante.

El TC delimita el objeto de la impugnación circunscribiéndolo al Acuerdo del Senado que aprueba las medidas adoptadas por el Gobierno, que es lo que se impugnaba por Podemos en el suplico de la demanda, aunque luego se interesó en las actuaciones la declaración de inconstitucionalidad de todas las disposiciones dictadas en desarrollo o complemento del Acuerdo. Se recuerda que —según reiterada jurisprudencia constitucional - el objeto del recurso queda fijado en la demanda, y que la declaración de inconstitucionalidad por conexión es una prerrogativa del Tribunal y no puede ser objeto de pretensión del demandante.

Las partes no discuten que el Acuerdo parlamentario tiene «fuerza de ley» y es susceptible de control en vía de recurso de inconstitucionalidad. El Tribunal confirma este entendimiento. Se aplican como precedentes el ATC 142/2017 y la STC 83/2016, referidos a la declaración del estado de alarma y su prórroga (artículo $116 \mathrm{CE}$ ). Unas resoluciones donde se reconoció que estas declaraciones pueden ser impugnadas en vía de recurso, pese a no ser formalmente leyes, porque autorizan a modificar temporalmente o desplazar la aplicación de normas legales. Sin perjuicio, de la fiscalización — se dijo- por los tribunales ordinarios de las disposiciones y actos dictados en su aplicación durante la vigencia del estado de alarma. La razón de decidir es la misma. Se afirma que el artículo $155 \mathrm{CE}$ «permite la constricción de la autonomía, con mayor o menor alcance, y, por lo mismo, la inaplicación excepcional de normas estatutarias y legales y su desplazamiento por las reglas mediante las que la Cámara, a propuesta del Gobierno, determine las concretas medidas a adoptar por el ejecutivo y discipline el régimen jurídico de esta intervención».

En suma, las declaraciones de los artículos 116 y 155 CE tienen — yo diríarango, fuerza y valor de ley, pues sólo pueden impugnarse ante el TC y permiten modificar y desplazar temporalmente otras leyes.

Obsérvese que se revisan las medidas adoptadas en el Acuerdo de intervención, pese a que algunas se agotaron con su uso y decayeron y otras sólo fueron de aplicación hasta la toma de posesión del nuevo Gobierno de la Generalidad tras las elecciones que se convocaron. Pese a la vigencia temporal de estas normas, se acuerda someterlas a control de constitucionalidad, para impedir que existan «ámbitos normativos inmunes al control de la jurisdicción constitucional» y asegurarse de la supremacía de la Constitución.

Resueltos estos óbices procesales, el TC decide aclarar primero las características de este procedimiento de intervención estatal y luego enjuiciar los vicios de inconstitucionalidad sustantivos. Se precisa pues la naturaleza del procedimiento del 
artículo 155 CE, calificando esta modalidad de control como «extraordinario». Se dice que supone una «vía específica de coerción directa» o un «medio extraordinario de coerción», para afrontar «incumplimientos inconstitucionales extremadamente cualificados». Una «medida de último recurso del Estado ante una situación de incumplimiento manifiesto y contumaz» o el «incumplimiento flagrante de obligaciones constitucionales impuestas». Se configura así un procedimiento de coerción sobre las Comunidades Autónomas que la Constitución confiere al Gobierno y al Senado, y no puede confundirse con un control de naturaleza competencial. Esta coerción estatal permite una injerencia —una constricción o limitación - en la autonomía territorial, para garantizar el principio de unidad en el que la autonomía se integra. El Gobierno y el Senado son aquí «garantes del ordenamiento integral del Estado». De ahí se desprende «que no cabe incoar este procedimiento sino cuando se esté ante una actuación autonómica que incumpla la Constitución...y no existan otras vías a través de las cuales se asegure el cumplimiento de la Constitución...y el cese del atentado al interés general».

Este procedimiento, en definitiva, sólo puede ser usado en circunstancias especialmente críticas y no cabe desdramatizarlo o normalizarlo como llegó a proponerse doctrinalmente por algunos autores hace décadas.

El artículo $155 \mathrm{CE}$ diferencia, en su tenor literal, el incumplimiento de las obligaciones que impongan la Constitución y las leyes, del atentado grave al interés general. Una diferenciación que no debe entenderse como exclusión o contraposición. Es una cláusula general babilitante para una intervención en la autonomía. El Tribunal integra ambas dimensiones.

Pero esto no implica que la aplicación del artículo 155 CE quede exenta de todo límite, abriendo una brecha en la estructura territorial del Estado. El fin de la intervención no puede ser otro que reestablecer el orden constitucional y el normal funcionamiento del sistema institucional. Las medidas que se adopten como necesarias deben responder a la finalidad de obligar a la Comunidad Autónoma a cumplir con sus obligaciones y proteger el interés general. Esta norma constitucional permite alterar temporalmente el funcionamiento normal del sistema. Pero no puede suponer una «suspensión indefinida de la autonomía» ${ }^{2}$. Tampoco permite la «supresión» de la Comunidad, ni limitar o excepcionar los derechos fundamentales de los ciudadanos, ni dar lugar a una limitación de la autonomía indefinida en el tiempo. El Tribunal insiste en que este procedimiento, por su propia naturaleza, obliga a dictar medidas temporales. Un aserto muy relevante.

2 Así se hizo por la Ley de 2 de enero de 1935, luego declarada inconstitucional por el Tribunal de Garantías Constitucionales el 5 de marzo de 1936, que dejaba en suspenso las facultades concedidas por el Estatuto de Autonomía al Parlamento de la Generalidad hasta que las Cortes, levantada la suspensión de garantías constitucionales, acordasen «el restablecimiento gradual del régimen autonómico» (artículo 1). El Tribunal sostuvo que tal suspensión indefinida podría convertirse en un medio de derogar prácticamente el Estatuto. 
Además, el artículo 155 CE no es el único medio de hacer cumplir la Constitución y las leyes. Sólo puede emprenderse este procedimiento cuando las vías de control jurisdiccional hayan resultado infructuosas. Es un último recurso. Afirmación con la cual el TC solventa un largo debate doctrinal previo. Pero claro está cabe acudir también a este mecanismo directamente si, a la vista de la contravención de la Constitución y de la actitud de las autoridades autonómicas, se «aprecie indubitadamente» que esas vías no serán satisfactorias. En definitiva, es un medio de control subsidiario y excepcional. El decantamiento de todos estos límites en la aplicación del artículo 155 CE me parece que tiene singular importancia.

El requerimiento con el que se abre el artículo $155 \mathrm{CE}$ identifica el presupuesto habilitante para iniciar el procedimiento ${ }^{3}$. Pero es simplemente una «constatación inicial», a juicio del Gobierno, con la finalidad u objetivo de dar oportunidad a que la obligación desatendida se cumpla voluntariamente. La falta de atención al requerimiento es una condición de procedibilidad, que el Senado debe controlar como también la verificación del presupuesto habilitante. Esta decisión del Senado puede someterse a la consideración del TC v.gr. si se negara el incumplimiento o el atentado al interés general, o si se discutiera si el requerimiento fue realmente desatendido, como se aseveraba en la contestación a la demanda.

El requerimiento pedía que cesara la «culminación de la deriva secesionista» de los órganos superiores de la Comunidad Autónoma, y la declaración, de 10 de octubre de 2017, «un supuesto manifiesto de constitución de la república catalana» como elemento de un llamado «proceso de transición nacional», entre cuyos hitos más relevantes estaban las leyes de 6 y 8 de septiembre de referéndum de autodeterminación y transitoriedad jurídica, que ya habían sido suspendidas por el TC. Pese a estas prohibiciones, el Gobierno de la Generalidad había impulsado un pretendido referéndum de autodeterminación el 1 de octubre. Así se identificaba el supuesto de hecho habilitante en el requerimiento. El TC admite que «no cabe duda alguna» de que efectivamente concurre el supuesto de becho habilitante del artículo $155 \mathrm{CE}$ por las reiteradas contravenciones de la Constitución y el Estatuto, que violaban el mandato de sujeción a la Constitución (artículo 9.1 CE) y atentaban contra el interés general de España, al cuestionar su unidad e integridad territorial, pretendiendo la ruptura del orden constitucional y crear un Estado catalán independiente en forma de república. Se recuerda que incluso el Presidente de la Comunidad compareció la víspera del requerimiento en el Parlamento de Cataluña presentando los datos del referéndum y firmando un documento o declaración que afirmaba la constitución de la República

3 Un detallado análisis de los aspectos de procedimiento siguiendo el llamado método de los pasos de origen germánico- puede leerse en J. GARCía TORRES, «El artículo 155 CE paso a paso» en VVAA, El artículo 155 de la Constitución, ob. cit., pp. 105-172. El autor recuerda que el artículo 37 de la Ley Fundamental de Bonn, de visible influencia en el artículo $155 \mathrm{CE}$, no exige un requerimiento previo. 
catalana y el inicio de un proceso constituyente. Unas actuaciones que «no hubieran podido ser reparadas en plenitud, ni revertidas sus consecuencias» .

El Presidente de la Generalidad respondió al requerimiento invocando el diálogo y la negociación, mas el Presidente del Gobierno de España entendió que se había desatendido el requerimiento previo sin resolver si alguna autoridad de Cataluña había declarado la independencia tal y como se preguntaba. Los recurrentes se oponían a este entendimiento, basándose en la ambigüedad de la respuesta. Pero el TC no admite estas objeciones, entre otras razones, porque el diálogo no puede versar sobre la sujeción a la Constitución y a las leyes: «los gobernantes son servidores, no señores de las leyes». También se desecha que el requerimiento estuviera falto de coherencia respecto de lo propuesto al Senado o respecto de lo manifestado en la posterior demanda, que — se reprochaba por los actores - se proyectaba sobre un conjunto de hechos más amplio. El TC concluye que el requerimiento inicial no solo se refería a la mencionada declaración de independencia sino a una serie de actuaciones que amenazaban la unidad del Estado. Igualmente se desestima que no hubiera correspondencia con las medidas propuestas al Senado, entre otras razones, porque el artículo 155 CE no impone al Gobierno la carga de enunciar en su requerimiento previo todas las medidas que piensa adoptar.

A mi entender, esta es otra pauta que debe ser reservada, la coherencia entre el requerimiento previo y el acuerdo de medidas adoptadas no reclama una absoluta identidad ni detalle. No en balde estamos en un extraordinario control político y no jurisdiccional.

Los Diputados recurrentes hacen suya la alegación de la Generalidad de que la autorización parlamentaria del Acuerdo estuvo viciada, porque se rechazó que compareciera el Delegado de la Generalidad en Madrid como representante del Presidente. De nuevo, el TC no acepta el argumento y recuerda que corresponde a la Cámara interpretar la legalidad parlamentaria (artículo 189 del Reglamento del Senado) en uso de su autonomía, y se recuerda que aún así se ofreció al Presidente comparecer en la Comisión conjunta o en el Pleno, unas posibilidades que fueron declinadas. Se precisa que este trámite no es más que la ocasión de ofrecer al Senado nuevas informaciones o argumentos que no consten en la documentación, algo que no se acredita. En suma, el Senado dispuso de los elementos necesarios para adoptar su decisión y no hubo indefensión alguna que quedara acreditada.

La demanda de Podemos y las representaciones del Gobierno y el Parlamento de Cataluña pretendían que el artículo 155 CE debe interpretarse limitándose a adoptar al mínimo necesario para no permitir una ruptura del modelo constitucional, y, en definitiva, agotarse en la impartición de instrucciones según afirma el apartado 2..$^{\circ}$ del precepto. Sin embargo, el TC razona - con acierto- que esta interpretación reduccionista no puede ser aceptada. El artículo 155 CE no especifica las medidas en que puede materializarse la coerción estatal y elude tasarlas. No cabe pues restringir en abstracto las modalidades necesarias de intervención, que 
dependerán de la gravedad del incumplimiento ${ }^{4}$. Los órganos del Estado tienen un margen de discrecionalidad. La Constitución ha dejado en manos del Gobierno y, en última instancia, del Senado, la determinación de las concretas medidas5.

Por otro lado, se agrega: «las instrucciones y la potestad de impartirlas...no son propiamente una medida, sino un excepcional instrumento jerárquico... puesto a disposición del Gobierno para conseguir ejecutar las medidas necesarias»; dos momentos diferentes y sucesivos (F.J. $\left.10^{\circ}\right)^{6}$. Se trata de una posibilidad, no de un límite a la actuación.

Esta distinción me parece que es algo alambicada y discutible y puede que fuera innecesaria, puesto que un tipo de medida en si misma puede ser dictar instrucciones a las autoridades autonómicas sin necesidad de otras actuaciones.

Tampoco — se dice— cabe deducir esa restricción por referencia al Derecho comparado, pues existen constituciones - la italiana, la austríaca o la portuguesa- que permiten, en casos extremos, la disolución, la suspensión o la sustitución de los órganos de una región. Por más que el valor del Derecho comparado sea meramente didáctico o ilustrativo. Tampoco del debate constituyente se extraen conclusiones en sentido restrictivo, concluye el TC.

Entre las «medidas necesarias» el Senado puede apoderar al Gobierno para subrogarse en funciones o competencias autonómicas, y ocupar el lugar de órganos de la Comunidad desplazando sus instituciones. La «sustitución» en el ejercicio de las relaciones competenciales no es factible normalmente, pero sí una vez iniciado el procedimiento del artículo 155 CE. Podría incluso producirse la «asunción integra» de todas las funciones de la Comunidad. Una sustitución por el Gobierno de la nación o quien designe. Esta caracterización de lo acecido como sustitución temporal de los órganos ha sido de estudio frecuente en la doctrina alemana y ha habido referencias en la nuestra.

El artículo 155 CE permite, en definitiva, constreñir la autonomía de una Comunidad Autónoma con el fin de reconducir su autonomía al marco

4 J. VinTRó, »El artículo 155 de la Constitución: marco jurídico y algunas reflexiones sobre su aplicación en Cataluña» El artículo 155 de la Constitución, ob. cit., p. 83, censura una concepción «extremadamente expansiva de las medidas». Pero me temo que no puede llegarse a otra conclusión en una interpretación constitucionalmente adecuada, como hace la sentencia, a la vista de la apertura de ese precepto, así como teniendo en cuenta la amplia gama de circunstancias diferentes en cada supuesto de hecho habilitante que el acuerdo de intervención debe ponderar. No en balde estamos en un Derecho de emergencia.

5 Puede consultarse J. García Torres, ob. cit., p. 139-140, donde se enuncian las medidas de coerción federal que se estiman procedentes en abstracto en la doctrina alemana, y aquéllas otras que se consideran improcedentes o ilícitas. La regulación alemana y la española no son la misma, pero pueden compararse. Sobre las diferencias entre el sistema del artículo 37 de la Ley Fundamental de Bonn y nuestro artículo 155, puede leerse J. García Roca, «Diez tesis sobre la intervención extraordinaria del Estado en las Comunidades Autónomas (artículo 155 CE) tras su aplicación en Cataluña» en El artículo 155 de la Constitución, ob. cit., pp. 173239, en especial pp. 180 y ss. La referencia constitucional al grave atentado al interés general de España transforma las cosas y las medidas que pueden adoptarse.

6 En J. García Roca, «Diez tesis...», ob. cit., p.220, se razona — citando a Orlando- que dictar instrucciones a una autoridad autonómica más que una sustitución entraña una relación temporal de jerarquía. 
constitucional y estatutario e imponerle el cumplimiento de sus obligaciones. La intervención coercitiva debe ser parcial o limitada en un doble sentido. De un lado, el ordenamiento autonómico debe pervivir en cuanto no resulte desplazado por las medidas adoptadas. Por otro, la coerción únicamente puede aplicarse sobre las actuaciones que guarden relación con el supuesto de hecho habilitante.

Además, las medidas habrán de ser las «necesarias». Los recurrentes entienden que «necesario» debe querer decir «proporcionado», es decir, no sólo deben ser adecuadas sino las menos gravosas para la autonomía. Modo de razonar al que no se oponía el Abogado del Estado. Sin embargo, el TC afirma — polémicamente- que el principio de proporcionalidad «no constituye en nuestro ordenamiento un canon autónomo». Es un principio que debe inferirse de preceptos constitucionales «siendo en el ámbito de los derechos fundamentales en el que normalmente resulta aplicable»; y conlleva tres juicios sucesivos (idoneidad, necesidad y proporcionalidad en sentido estricto). La demanda insiste en el juicio de necesidad. Pero el TC establece que esta propuesta no puede ser compartida y el criterio del medio más benigno o menos gravoso no puede ser empleado por su jurisdicción, pues entonces ocuparía el lugar que la Constitución ha reservado al Gobierno y al Senado en la determinación de la necesidad de la medida. La decisión puede ser enjuiciada, pero respetando un margen de apreciación y sin realizar un juicio de intenciones políticas. Se trata de un «juicio externo» «sin sustituir el juicio político ni formular hipótesis sobre la viabilidad de otras alternativas». El juicio debe llevara examinar si las decisiones resultan «razonables» en función de las circunstancias del caso. Esta estimo que es la parte más controvertida de la fundamentación jurídica y luego me centraré en ella, para revisar sus consecuencias. El TC opta por un test de razonabilidad de las medidas y no por un juicio de necesidad, ligado a la proporcionalidad.

La adopción, el cumplimiento y la ejecución de las medidas corre a cargo del Gobierno, que no actúa estrictamente como poder ejecutivo sino como «órgano constitucional garante de la integridad de la norma suprema», en defensa del interés general del Estado en estas situaciones de crisis constitucional. Debe actuar de conformidad con lo autorizado en el Acuerdo del Senado, para reconducir la Comunidad Autónoma al orden constitucional y estatutario que es la finalidad que el artículo 155 CE persigue. Excluyendo eso sí el ejercicio de potestades legislativas por el Gobierno. Pero sí cabe interferir con medidas en el Parlamento autonómico siempre que sean temporales.

A la vista de cuanto precede, se inicia la revisión de las concretas medidas adoptadas que — ya hemos visto— - se califican de «sustitución orgánica». Se razona que el Gobierno justificó la pertenencia de las mismas en su propuesta al Senado quien las valoró y aprobó ante una situación en que el Gobierno de la Generalidad había provocado una grave crisis constitucional al proclamar una república catalana. De manera que no pueden tacharse de excesivas las medidas de cese y sustitución del Presidente, el Vicepresidente y otros miembros del Consejo de Gobierno, ya que «actuaban como un mero poder de hecho». Carece de lógica 
pensar que estas autoridades pudieran ser las encargadas de restablecer la integridad de la legalidad constitucional. Los mismos razonamientos deben aplicarse a las supuestas vulneraciones de los derechos de participación política (artículo 23.2 CE) de los titulares de estos órganos y otros derechos invocados. De forma lapidaria, pero irrefutable, se concluye «no existen para los gobernantes derechos sin Derecho» y no se aviene a la más elemental razón jurídica, pretender ser titular de un derecho subjetivo «con abuso y usurpación del poder público... frente a un ordenamiento cuya fuerza de obligar expresamente menosprecia».

Respecto de la disolución del Parlamento, los recurrentes argumentaban que esta posibilidad quedó expresamente desechada en el proceso constituyente ${ }^{7}$. Pero el TC ya había rechazado este argumento esgrimido en ambas demandas y añade ahora que esta medida puede autorizarse por el Senado siempre que se «necesaria» atendiendo a la situación creada. Si bien no cabe «sustituir permanentemente» a la Cámara autonómica en el ejercicio de sus funciones, pues el Gobierno no puede actuar como un legislador ordinario ni cabe menos aún su supresión que entrañaría una suspensión indefinida del autogobierno. Esta medida encuentra cobertura en la cláusula abierta y «flexibilidad constitucional» del artículo $155 \mathrm{CE}$. Por otro lado, ningún «mandato popular» puede nunca amparar a un Parlamento para incumplir el Derecho. El Parlamento de Cataluña se ha alzado frente a la soberanía nacional, residenciada en el pueblo español, «convocando a una fracción de ese pueblo, en desafío a la unidad de la Nación, a decidir la suerte del Estado». En concreto, las resoluciones de ese Parlamento de 27 de octubre denominadas «Declaración de los representantes de Cataluña»y «Proceso constituyente» plasman la voluntad de eludir los procedimientos de reforma constitucional. Ningún poder constituido puede situarse por encima de la norma fundamental. La disolución del Parlamento con una simultánea convocatoria de elecciones pretende la «recuperación del marco constitucional y estatutario», preservando el autogobierno autonómico por quienes sean elegidos. La medida se orienta a una pronta conclusión de la intervención, aunque como sabemos las cosas no se produjeran de este modo por los problemas en la investidura presidencial.

En relación a las medidas dirigidas a la Administración autonómica, sometida a un régimen de autorización o comunicación previa, se afirma que el Acuerdo del Senado permite desplazar normas legales sobre el procedimiento administrativo y sustituirlas por otras regulaciones temporales en atención a las graves circunstancias. Es una medida necesaria, pues está al servicio de la ejecución de las

7 También J. Vintró, ob. cit., p, razona que la disolución del Parlamento de la Generalidad fue improcedente y violaba la autonomía política. En sentido contrario, he defendido que la suspensión de una asamblea revolucionaria era la única medida posible para defender el autogobierno y la vigencia del Estatuto de Autonomía y el Reglamento del Parlamento que habían sido claramente transgredidos a los ojos incluso del Consejo de Garantías Estatutarias y de los propios Letrados de la Cámara. Véase J. García RocA, ob. cit., p. 225 y ss, epígrafe «Es posible la disolución del Parlamento y la convocatoria de elecciones». 
medidas aprobadas en el Acuerdo del Senado. Impartir instrucciones a las Administración intervenida es una forma de hacer valer la jerarquía entre el titular de esta potestad extraordinaria de control y sus subordinados, sin perjuicio de la existencia de unas garantías jurisdiccionales.

Entre otros extremos que no puedo reseñar, el mencionado Acuerdo igualmente prescribía que los órganos o autoridades que designe el Gobierno de la nación dispondrán de las facultades de ordenar la publicación de las resoluciones, actos o disposiciones normativas, cualquiera que sea su rango, en el Diario Oficial de la Generalitat o en el del Parlamento de Cataluña; y, de forma complementaria, se agregaba que las publicaciones realizadas en contra de lo acordado por esas autoridades determinarán su falta de vigencia. En definitiva, un régimen también de comunicación previa sobre las publicaciones oficiales. La demanda invocaba la seguridad jurídica (artículo 9.3 CE). El TC concluye que se trata — de nuevode una sustitución temporal, adecuada a la situación creada. Pero la reacción ante la eventual publicación no autorizada, efectivamente viola la seguridad jurídica al tener por ineficaz o no verificada la publicación. Este párrafo segundo del apartado E.3 es el único que se declara inconstitucional de todo el Acuerdo impugnado.

En lo que atañe a la policía de la Generalidad, los Mossos d'Esquadra, se atribuían las funciones del Consejero de Interior y otras autoridades a los órganos o autoridades designados por el Gobierno de la nación, quienes podían dictar instrucciones. El TC recuerda que el artículo $155 \mathrm{CE}$ permite limitar o modular las competencias autonómicas en el grado en que el Gobierno y el Senado consideren necesario en atención a las graves circunstancias, y así había ocurrido con las competencias sobre seguridad y orden públicos.

Finalmente, el Acuerdo del Senado establecía algunas restricciones o limitaciones al funcionamiento del Parlamento de Cataluña — en las funciones de control e impulso, la investidura presidencial y la admisión de iniciativas legislativas irregulares - hasta la constitución del nuevo tras las elecciones. El TC precisa que estas medidas no tuvieron efectividad alguna tras la inmediata disolución y convocatoria de elecciones; y advierte que tienen asimismo que ver con la sustitución del Presidente y los miembros del Gobierno, pasando el Gobierno de la nación a ejercer sus funciones ante la excepcionalidad de la situación. Tampoco pueden considerarse inconstitucionales porque vaya dirigidas al Parlamento. Menos aún se lesionan los derechos políticos de los parlamentarios, porque son derechos de configuración legal dentro de una determinada forma de gobierno parlamentaria que ha sido excepcionada pro tempore. Si bien se añaden las reservas a la aplicación en el procedimiento del artículo 155 CE de «las genéricas invocaciones a la proporcionalidad», pues «es patente que la exclusión de todo control político sobre los órganos o autoridades llamados a desarrollar y ejecutar el Acuerdo es condición inherente a su carácter de intervención coercitiva».

En virtud de estas razones se estima parcialmente la demanda únicamente en lo que atañe al párrafo segundo del apartado E.3 sobre la invalidez de la 
publicación no autorizada de resoluciones, actos o disposiciones, desestimándose el recurso en todo lo demás.

\section{LA STC 90/2019}

Esta segunda sentencia afirma ella misma que recoge en lo sustancial lo ya razonado en la STC 89/2019. Con carácter específico, enuncia con detalle las disposiciones que se dictaron en desarrollo del Acuerdo del Senado y se impugnaron en la demanda: diversos decretos y órdenes ministeriales sobre el cese del Presidente de la Generalidad y los Consejeros, sobre designación de los órganos y autoridades encargados de dar cumplimiento a las medidas, respecto de la organización de la Generalidad y la convocatoria de elecciones, etc. La demanda solicitaba la nulidad del citado Acuerdo «en su conjunto». Pero, de nuevo, el TC delimita el objeto del recurso excluyendo este planteamiento de la supuesta unidad normativa al carecer tales disposiciones de fuerza de ley, no «caber impugnaciones globales», y no haber sido especificadas en el suplico de la demanda, lo que lleva en el fallo a inadmitir parcialmente el recurso en este extremo. Poco o nada hay de nuevo en el resto de los fundamentos jurídicos de esta segunda sentencia.

\section{ALGUNAS CUESTIONES A DISPUTAR: LA EXCLUSIÓN DEL JUICIO DE NECESIDAD Y PROPORCIONALIDAD, Y LA REVISIÓN DE LAS DISPOSICIONES Y ACTOS EN DESARROLLO DEL ACUERDO DEL SENADO}

\section{V.1. Algunos estándares a reservar}

Carece de sentido que recapitule, con detalle, la forma en que el TC ha interpretado el artículo $155 \mathrm{CE}$ tanto por la claridad del pronunciamiento que acaba de reseñarse como para no afrontar el riesgo de que se pierdan los matices. Pero acaso convenga reiterar algunos estándares y retenerlos en la memoria.

La intervención ex artículo 155 CE es una última ratio, cuando las vías jurisdiccionales o de otro tipo fueran infructuosas ante la contumacia de los órganos intervenidos, tras el incumplimiento flagrante de las obligaciones constitucionales y legales o un grave atentado al interés general. Es un medio extraordinario de coerción que permite limitar el autogobierno y sustituir temporalmente a los órganos autonómicos en el ejercicio de algunas de sus competencias y facultades con la finalidad de restituir lo antes posible el orden constitucional y estatutario. Un control subsidiario y excepcional, que no puede devenir en normal o cotidiano sin incurrir en abuso.

Además esta intervención no puede ser total sino parcial y viene sujeta a límites y garantías constitucionales. No cabe una suspensión indefinida de la 
autonomía, una intervención sin plazo, ni un direct rule, ni una supresión de la Comunidad Autónoma sin reformar la Constitución, ni privar de derechos fundamentales a los ciudadanos sin declarar un estado de emergencia (artículo 116 CE). Las medidas que pueden dictarse por el Gobierno y el Senado en el Acuerdo de intervención deben ser «necesarias», por expreso mandato constitucional, y resultar adecuadas al supuesto de hecho habilitante, a la gravedad del incumplimiento o atentado al interés general.

No existe un enunciado constitucional de medidas sino una cláusula abierta y, ante esa flexibilidad constitucional, son el Gobierno y el Senado como órgano generales de todo el Estado quienes deben especificarlas. Entre ellas cabe, la disolución del Parlamento autonómico de forma simultánea a la convocatoria de elecciones, o el cese de autoridades que actuaron con contumacia como meros poderes de hecho, quebrantando la Constitución y el Estatuto y desobedeciendo reiteradas sentencias constitucionales, y también someter a un régimen de instrucciones y autorizaciones previas la actividad del Gobierno y la Administración intervenida en cuestiones relacionadas con el supuesto de hecho habilitante. Las medidas posibles no se agotan en dictar instrucciones que ni siquiera son en sentido estricto medidas según defiende el TC.

Ningún pretendido mandato popular ampara incumplir el Derecho. El Parlamento no muere si se convocan inmediatamente elecciones autonómicas. El Gobierno de la nación puede subrogarse en lugar de las autoridades autonómicas, sustituirlas temporalmente y asumir algunas de sus competencias. Una sustitución temporal en algunos aspectos del autogobierno, precisamente para preservar la autonomía territorial frente a sus enemigos y volver al orden constitucional. Pero el Gobierno interventor no puede aprobar leyes. Sin embargo, el Acuerdo del Gobierno y el Senado permite modular y desplazar temporalmente las normas previstas en las leyes vigentes.

\section{V.2. El juicio de necesidad de las medidas}

Sentada esta interpretación constitucional por el intérprete supremo de la Constitución, quiero señalar dos cuestiones que creo merece la pena disputar, pues no hay Derecho ni pensamiento jurídico sin discusión. La Constitución y el TC mantienen que las medidas habrán de ser «necesarias», y los recurrentes sostenían — tesis a la que no se oponía el Abogado del Estado lo que corrobora que no era manifiestamente inadecuada- que «necesario» quiere decir «proporcionado». Al igual que habían defendido antes de las sentencias la práctica totalidad de los autores al analizar el artículo $155 \mathrm{CE}$, pues la calificación de las medidas en el apartado $1 .{ }^{\circ}$ como «necesarias» parece naturalmente abocar a un juicio de necesidad de la medida como integrante del juicio de proporcionalidad. Sin embargo, la STC 89/2019 rechaza la aplicación de la proporcionalidad, porque — dice — no es un «canon autónomo» en nuestro ordenamiento y su ámbito natural es el de 
los derechos fundamentales; lo que le lleva a concluir que el criterio de la medida «menos benigna o gravosa» no puede ser empleado por la jurisdicción constitucional, para no ocupar el lugar que el artículo 155 CE reserva al Gobierno y al Senado en la determinación de la necesidad de la medida. La decisión puede ser enjuiciada, — - se dice - pero respetando un margen de apreciación y sin realizar un juicio de intenciones políticas. Un juicio externo que lleve a examinar si las decisiones resultan «razonables» en función de las circunstancias del caso.

A mi entender, es un hecho que la proporcionalidad no se aplica sólo respecto de derechos fundamentales, pues aunque no lo diga claramente así la sentencia, puede que subyazca esta idea para excluir su aplicación de la intervención coercitiva junto a su caracterización como una decisión política. Así es conocido que el principio surgió en el Derecho sancionador en Prusia. Se usa por el Tribunal de Justicia que no es sólo un tribunal de derechos y en muchas normas del Derecho de la Unión. Se ha convertido en un principio universal en el constitucionalismo, creciendo día a día en su utilización. Es hoy el principio más habitual en la interpretación constitucional en muchos tribunales ${ }^{8}$. Salvo la Supreme Court de los Estados Unidos muy circunscrita al balancing de los intereses y aislada del trabajo judicial en red.

Bien es verdad que se ha construido especialmente sobre las limitaciones a los derechos fundamentales. Pero no sólo se aplica allí. La Carta de Derechos Fundamentales de la Unión (artículo 52) incluye el respeto al principio de proporcionalidad a la hora de introducir «limitaciones» y determinar el alcance de los derechos garantizados. Mas nada impide sino antes bien aconseja utilizar el principio de proporcionalidad para revisar la constitucionalidad de otras limitaciones legales o interferencias a bienes constitucionales con las especificidades que sea preciso decantar en cada ámbito9. De hecho, el principio de proporcionalidad constituye igualmente una pieza clave en el control del ejercicio de las competencias de la Unión según el artículo 5.4 TUE que lo recoge expresamente junto a la subsidiariedad.

Al cabo, la proporcionalidad está indisolublemente ligada no sólo a preceptos constitucionales (a mi juicio en el artículo 155.1 CE) sino a la ideas de Estado de Derecho, democracia constitucional e incluso al conflicto entre principios legales, y resulta inmanente a estas mismos conceptos como han razonado diversos autores ${ }^{10}$; e incluso se relaciona directamente con la misma idea de Derecho,

8 Vid J. García Roca, La transformación constitucional del Convenio Europeo de Derechos Humanos, Thomson Reuters Civitas, Madrid, 2019, epígrafe «Un instrumento constitucional del orden público europeo y una interpretación more Constitutionalis. El principio de proporcionalidad ...» y la bibliografía que allí se cita.

9 Véase, entre otros, L. ORTEGA, «El principio de proporcionalidad como garante de la autonomía local» en Font Y Llovet, T. (Dir.), Anuario de Gobierno Local 1997, pp. 99-115.

10 Puede leerse la obra del Presidente del TS de I. A. BArak, Proportionality, Constitutional rights and their limitations, Cambridge U.P., 2010, pp. 211 y ss, sobre las relaciones entre proporcionalidad y democracia y Rule of Law. 
que impide el exceso y el daño injustificado y demanda la proporción o equilibrio entre las cosas.

El propio Estatuto de Autonomía de Cataluña alude expresamente el principio de proporcionalidad al regular la participación del Parlamento en los procedimientos de control de los principios de subsidiariedad y proporcionalidad que establezca el Derecho de la Unión en relación con las propuestas legislativas europea (artículo 188). También el artículo 8.3 de la Carta Europea de Autonomía Local de 1985 establece que «el control administrativo de las Entidades locales debe ejercerse manteniendo una proporcionalidad entre la amplitud de la intervención de la autoridad de control y la importancia de los intereses que pretende salvaguardar». Una previsión que tiene alguna similitud con la que nos ocupa, ya que también se suscita respecto de la limitación de una intervención en un ente territorial, aunque no sea de la misma entidad que la del artículo $155 \mathrm{CE}$, pues se piensa en el control sobre los actos. Igualmente dice que los recursos financieros deben ser proporcionales a las competencias previstas (artículo 9). Asimismo se ha argumento la conveniencia de la introducción de los principios de subsidiariedad — ligado al fin de la medida — y proporcionalidad — centrado en la entidad de la interferencia - en una solución más estructurada, formalizada y predecible de los conflictos de competencias territoriales ${ }^{11}$.

Podríamos seguir razonando en esta línea pero, en definitiva, cabe concluir que la proporcionalidad se proyecta sobre espacios distintos a los derechos, en particular ligados a las relaciones entre entes territoriales, e igualmente propios de una interpretación de normas constitucionales, en especial, cuando hablamos de intervenciones, restricciones o limitaciones a bienes constitucionalmente protegidos.

Por el contrario, el viejo juicio de razonabilidad — que la sentencia asumede las medidas no ha estado nunca exento de numerosas críticas doctrinales por su imprecisión e indeterminación, y suele producir escrutinios más laxo; con su uso se pierde en garantías y se añade en indeterminación como ha ocurrido con la construcción jurisprudencial de la inmensa tutela judicial efectiva. Es comúnmente aceptado que el test del límite razonable o justificable — que adoptan el artículo 36 de la Constitución de Sudáfrica de 1996, y, con menor claridad, el artículo 1 de la Canadian Charter of Rights and Freedoms de 1982- suele ser más flexible.

Sobre todo, se aplica el principio de proporcionalidad, de forma muy estructurada, en el control de convencionalidad que hacen las sentencias del Tribunal Europeo de Derechos Humanos que tienden a centrarse en la «necesidad de la medida en una sociedad democrática», según demandan expresamente los

11 Puede leerse J. García Roca e I. García Vitoria, «La división territorial del poder y la garantía constitucional de la autonomía local (art. 137)» en M. RodríGUEZ-PIÑERo y M.E. CASAS (dir.), Comentarios a la Constitución española, BOE-Kluwer, p. 988. 
artículos 8 a 11 del Convenio Europeo de Derechos Humanos, unificando los juicios de necesidad y proporcionalidad en sentido estricto en uno sólo. Me parece muy aconsejable un paralelismo o simetría con los métodos de exégesis del TEDH toda vez que puede posteriormente revisarse en amparo europeo de derechos algunas decisiones del TC.

No obstante, en Sher y otros contra el Reino Unido, de 20 de octubre de 2015, se rechazaron las violaciones de derechos de unos pakistaníes detenidos en aplicación de la legislación antiterrorista; una legislación de emergencia ante una grave amenaza como ocurre en el artículo 155 CE. El Tribunal Europeo admitió que la amenaza terrorista permite investigaciones policiales más amplias de las habituales, dada la gravedad de la situación y el riesgo para las vidas de muchas personas, añadiendo que los actores tenían un remedio en la revisión judicial de las quejas $^{12}$.

Con similitud a la cuestión que nos ocupa, el TEDH ha aplicado igualmente el juicio sobre necesidad de la medida a supuestos de aplicación del artículo 15 del Convenio Europeo de Derechos Humanos, que permite derogar o suspender las obligaciones previstas en el mismo en caso de guerra o de otro peligro público que amenace la vida de la nación. Realmente, el Tribunal Europeo no revisa el supuesto de hecho habilitante, un extremo muy político, sino las medidas adoptadas para asegurarse de que sean realmente una respuesta a la situación de emergencia; atendiendo a elementos como son la naturaleza de los derechos suspendidos, la duración del estado de emergencia y las circunstancias que lo han ocasionado ${ }^{13}$. En definitiva, el TEDH revisa la correcta aplicación de la suspensión siguiendo su habitual juicio de proporcionalidad que integra el juicio de necesidad de la medida. Si los Estados tienen un margen de apreciación de la suspensión, existe un control europeo de adecuación a las normas del Convenio, una vez activado el mecanismo, incluido por el Tribunal Europeo si hubiere una demanda interestatal o individual ${ }^{14}$.

La aplicación de la proporcionalidad, normalmente más estricta o rigurosa que la muy laxa razonabilidad, no impide ponderar adecuadamente situaciones de emergencia y graves amenazas en un Estado de Derecho como es la intervención coercitiva. Basta con limitar o restringir la intensidad del juicio de necesidad de la medida en una prudente autocontención o self-restraint en función del objeto. Ciertamente, cabe respetar un «margen de apreciación» a los órganos constitucionales competentes en la aplicación de este test de proporcionalidad, pues no es lo mismo la intensidad de la revisión de un derecho absoluto como es

12 Vid M. RocA, «La suspensión del Convenio Europeo de Derechos Humanos desde el Derecho español: procedimiento y controles» en Revista Española de Derecho Europeo, epígrafe 4, de próxima publicación.

13 Idem y la bibliografía sobre derogación del Convenio que allí se cita.

14 Así lo sintetiza P. A. Fernández, «La suspensión de las garantías establecidas en el Convenio Europeo de Derechos Humanos (art. 15)» en J. García Roca y P. SANTOlaya (Coords.), La Europa de los Derechos. El Convenio Europeo de Derechos Humanos, CEPC, Madrid, 2014. 
el derecho a la vida que v.gr. en los sistemas electorales donde el control judicial no debería ser estricto, pues existe un amplio margen de apreciación. En definitiva, la intensidad del escrutinio judicial puede depender del objeto y la naturaleza del derecho. Conviene recordar McCann contra el Reino Unido, de 27 de septiembre de 1995, donde se exigió un control estricto del derecho a la vida, y se advierten bien las diferentes consecuencias del uso razonable de la fuerza por la policía y un más estricto test de proporcionalidad y necesidad de la medida. Pero, en sentido contrario, hay también muchos ejemplos de deferencia y autocontención v.gr. respecto de los sistemas electorales que reflejan decisiones nacionales muy políticas, así el Caso Yubmak y Sadak contra Tuquía, de 8 de julio de 2008, sobre la barrera electoral.

Estimo pues cabal defender que al afrontarse la necesidad de las medidas adoptadas en aplicación de un control extraordinario y político sobre las Comunidades Autónomas (artículo 155 CE), ante una gravísima situación de emergencia como es la que analizamos, la jurisdicción constitucional debe conceder una deferencia a los órganos generales del Estado. El TC debería limitarse a rechazar medidas manifiestamente desproporcionadas, inadecuadas a la entidad del incumplimiento o del atentado e inhábiles o innecesarias para reparar el orden constitucional amenazado. No debería revisarse normalmente la apreciación del supuesto de hecho habilitante por el Gobierno, tras el control del Senado, salvo manifiestos abusos, pero si cabria enjuiciar la necesidad de las medidas. Es ciertamente preciso respetar un margen de apreciación a los dos órganos constitucionales de dirección política que toman la decisión, pero ese margen no puede ser absoluto o desprovisto de límites. Resulta muy discutible negar, como hace el TC, que las medidas que apruebe el Senado deban responder al criterio de la intervención mínima o menos gravosa. Haciendo esta revisión el TC no ocuparía el lugar del Gobierno y el Senado, pues no es lo mismo elegir las medidas adecuadas entre un haz de actuaciones complejas que controlar sus excesos.

Respecto del «control externo» que asume el TC, la idea es correcta, pero queda eclipsada por el rechazo del test de necesidad y la proporcionalidad. Esta tesis sí puede compartirse. De hecho, el TJUE practica esta actitud deferente en su jurisprudencia sobre división de competencias entre la UE y los Estados. En la sentencia Reino Unido contra Consejo (Caso C.84/94), el TJUE sostuvo que el control judicial debe limitarse a examinar si la decisión del Consejo de aprobar un acto legislativo está viciada por error manifiesto o abuso de poder, o si ha manifiestamente excedido de su discrecionalidad. El TC podría incorporar estos estándares para caracterizar este control externo que asume.

Con idéntica razón de decidir, sólo se revisa por el TC la «extraordinaria y urgente necesidad» como presupuesto de hecho habilitante del decreto-ley (artículo $86 \mathrm{CE}$ ), en cuanto decisión política del Gobierno, en casos de manifiesta inexistencia de urgencia y para frenar abusos gubernamentales. Pero ese control no menos excepcional de un tribunal constitucional no debe negarse, pues esos abusos gubernamentales ocurren cada vez con más frecuencia. 
En conclusión, creo que la proporcionalidad es un principio habitual de la interpretación constitucional en distintos ámbitos, también en las relaciones entre entes territoriales — de competencia, colaboración o conflicto- ${ }^{15}$ y no sólo en derechos fundamentales, y debería ser usado al revisar la proporción o equilibrio de una intervención estatal en la autonomía constitucional y autogobierno de una Comunidad Autónomas, para impedir excesos y medidas innecesarias y desproporcionadas, o claramente inadecuadas para volver al orden constitucional. Mas —insistiré- la proporcionalidad demanda la «adecuación» entre las medidas adoptadas y la gravedad del supuesto de hecho o amenaza habilitante de la intervención coercitiva, y debe tener en cuenta la intensa dimensión política de esta situación de emergencia y la gravedad del atentado a la Constitución para practicar una autocontención judicial en función del objeto.

Ante un gravísimo atentado al interés general como fue el ocurrido en 2017 en Cataluña, un intento de destrucción de la Constitución y del Estatuto de Autonomía y de sustitución revolucionaria ${ }^{16}$ del poder constituyente, un inevitable juicio de constitucionalidad y de necesidad de la medida, ciertamente debe llevar a un control «externo» - como dice el TC_- esto es, limitado o restringido. No debe sustituirse al Gobierno y al Senado en su juicio político como órganos generales del Estado a los que la Constitución encomienda la difícil tarea de recuperar el orden constitucional, pero corresponde al TC impedir el exceso.

Por lo demás, el Tribunal Constitucional no niega la posibilidad de una revisión jurisdiccional de las medidas y de hecho lo hace con prudencia y acertadamente en estas dos sentencias. De suerte que, pese a la doctrina general que el TC sienta, quizás contenida o moderada en exceso, luego se revisan cabalmente todas las medidas adoptadas y se declaran conformes con la Constitución. La doctrina general no ha producido en este caso merma alguna de las garantías.

Los ingleses gustan decir «the proof of the pudding is in the eating»: no se puede hablar de las cosas hasta probarlas. Puede que mediante el empleo de una proporcionalidad y necesidad restringidas, como defiendo e invocaban los recurrentes y el Abogado el Estado, y la tesis que el TC construye de forma algo imprecisa, ligada a la razonabilidad y rechazando el juicio de necesidad, no haya tanta diferencia en la práctica y acabe por llegarse al mismo resultado. Pero puede que no sea así siempre lo que me parece un riesgo innecesario. La tesis de la proporcionalidad restringida, que incluye la necesidad, me parece más garantista que este control externo de razonabilidad, con todo sincero respeto al interprete supremo

15 J. García Torres, ob. cit., nota al pie 228, recuerda que también el Tribunal Constitucional Federal Alemán no considera aplicable el principio de proporcionalidad a las relaciones competenciales entre Bund y Länder, que — dice_ - sirve sólo para los derechos fundamentales, pero sigue el principio de relación federal amistosa (Bundesfreundlichen Verblaten), que le permite llegar a los mismos resultados; y asimismo advierte que muchos autores consideran preferible aplicar directamente la proporcionalidad.

16 J. GARcía RocA, «Después del espectáculo revolucionario: deliberar, votar, reformar, rezar....» en El Cronista del Estado social y democrático de Derecho, 2017, n. ${ }^{\circ} 71-72$, pp. 20-23. 
de la Constitución, y más adecuada al tenor literal del artículo 155.1 CE que se refiere expresamente a la necesidad de las medidas.

Para alejar temores, de la misma racionalidad y prudencia que se supone del TC y en estas sentencias ha practicado, es de esperar que en el uso de un juicio de proporcionalidad restringido, por la naturaleza del objeto de enjuiciamiento, no se practiquen controles no menos desproporcionados, por intensos, que las medidas que se revisan.

Si efectivamente el caso llegara, podría bastar, sin cambiar la doctrina jurisprudencial que ahora se acuña, con no autoimponerse el TC limitaciones innecesarias, en un control externo y restringido de las medidas, que se antojaran excesivas, al detectarse como evidentes otras menos radicales, o de aquellas medidas que no estuvieran directamente ligadas realmente con la finalidad de la intervención. Una emergencia y una intervención de este entidad reclaman controles para no dañar la Constitución al defenderla.

Dos caminos diferentes para llegar al mismo sitio, pero puede que no siempre. Conviene asegurarse de que en el uso de una herramienta tan radical y arriesgada como es la intervención coercitiva del artículo 155 CE, que puede quebrar la Constitución al defenderla, no se produzcan excesos y abusos, fruto de medidas claramente innecesarias. Ya nos enseñó Hamilton que toda mayoría tiene intereses inmediatos o pasiones momentáneas, y, en los últimos años en España, la frase no se me va de la cabeza.

\section{V.3. Disposiciones y actos en desarrollo del Acuerdo}

En segundo lugar, el TC decidió inadmitir en parte el recurso de inconstitucionalidad presentado por el Parlamento de Cataluña y rechazar la pretensión de Podemos, posterior a la demanda, de revisar el Acuerdo de intervención del Senado «en su conjunto», es decir, integrado por las disposiciones y actos que se dictaron en su desarrollo. Se negó que estas normas tuvieran rango y fuerza de ley y se recordó que es jurisprudencia constitucional muy reiterada que no caben «impugnaciones globales» en un control normativo de las leyes.

La decisión y el razonamiento me parecen impecables y garantistas. Sin embargo, no ha faltado alguna crítica doctrinal en la que se sostiene de forma muy lacónica que esta «interpretación es incoherente», porque si se admite que el Acuerdo del Senado está dotado de fuerza de ley, para alterar temporalmente el funcionamiento de la Comunidad Autónoma, también debería haberse reconocido la misma fuerza de ley a las medidas del Gobierno que son imprescindibles para conseguir ese resultado ${ }^{17}$. Pero esta crítica es inadecuada, hay aquí un salto

17 M. Satrústegui, «Enredarse innecesariamente» en El País, 23 de julio de 2919, p. 13. También J. ViNTRó, ob. cit., p. 84, sostiene — de forma algo apodíctica- que la naturaleza que la naturaleza de fuerza de ley debería extenderse a los decretos dictados en desarrollo del Acuerdo y bajo su cobertura. Una tesis que el TC acertadamente rechaza. 
en el razonamiento y en el reproche y no advierto que exista contradicción alguna sino todo lo contrario. Así un reglamento de desarrollo legislativo puede ser inevitable para aplicar una ley y alcanzar sus resultados en la práctica, pero eso no otorga rango legal al reglamento.

En mi trabajo sobre el artículo $155 \mathrm{CE}^{18}$ he razonado que desde luego caben controles judiciales de la aplicación de las medidas aprobadas en el Acuerdo de intervención como garantía, si hubiere abusos, excesos o desviaciones de poder y a instancias de los órganos y autoridades afectadas. No puede bastar con las garantías derivadas de la participación de la Comunidad intervenida en el procedimiento de aprobación del artículo $155 \mathrm{CE}$, es menester garantizar asimismo la regularidad en el momento de su ejecución para evitar indefensiones y ámbitos exentos de jurisdicción en un Estado de Derecho. Pero el TC no puede ni debe revisar todo eso y de una sola vez como pretendían los actores defendiendo la posición de la impugnación conjunta. Desde luego podrían impugnarse disposiciones y actos ante la jurisdicción contencioso administrativo e incluso en vía de amparo de derechos o de conflicto de competencias ante el TC si hubiere razón bastante para cada uno de ellos.

La colaboración de las jurisdicciones contencioso administrativa y constitucional lejos de ser un enredo es una garantía, pues el TC no pude desbordar el contenido de su jurisdicción y revisar la regularidad de un amplio número de disposiciones y actos administrativos que pueden tener impugnaciones fundadas en razones propias y diferentes. El TC no se ha enredado en su propia tela de araña sino que ha mantenido sus precedentes y ha abierto una puerta a la colaboración judicial.

\section{A MODO DE CONCLUSIÓN}

El TC ha interpretado con prudencia el artículo 155 CE tras su primera aplicación, de forma razonada y moderada, admitiendo el carácter excepcional —y no ordinario o normalizado- de la intervención coercitiva del Estado, que debe producirse en defecto de otros controles judiciales sobre los actos de las CCAA siempre que sea posible.

Se reconoce que un amplio abanico de medidas pueden aprobarse en función de la entidad del incumplimiento o atentado al interés general, incluido la sustitución temporal de las competencias autonómicas y sus autoridades y su sometimiento a autorizaciones previas o instrucciones. Dictar instrucciones no es la única actuación posible. Pero no todo vale. Existen una serie de limites que el Tribunal ha decantado. La revisión de la necesidad de las medidas aprobadas debe reconducirse a un juicio de razonabilidad o control externo, y no a un juicio de

18 J. García Roca, «Diez tesis sobre la intervención extraordinaria ...» ob. cit., epígrafe «Diversidad de medidas, principio de proporcionalidad y controles jurisdiccionales de su aplicación», pp. 219 y ss. 
proporcionalidad y de equivalencia de las medidas buscando la menos gravosa para los afectados. Si bien estimo que, en este último extremo, debía haberse razonado de otra manera y admitir unos juicios de necesidad y proporcionalidad restringidos o limitados por la entidad de la amenaza y el carácter muy político de la decisión, un control no estricto sino deferente con la decisión de los dos órganos constitucionales a los que la Norma fundamental asigna la responsabilidad de la decisión. De hecho, el TC ha revisado la constitucionalidad de todas las medidas impugnadas. Finalmente, la jurisdicción contencioso-administrativa puede colaborar con la constitucional para asegurarse de la regularidad en la aplicación del Acuerdo.

Ojalá el artículo 155 CE no tenga que volver a aplicarse por la contumacia de la autoridades secesionistas en incumplir las leyes y la desobediencia ${ }^{19}$, pero su procedimiento de aprobación, las medidas que pueden adoptarse, y los límites que no pueden superarse son ahora mucho más nítidos tras estas sentencias. No deberíamos alejarnos del tempo moderato que han interpretado el Acuerdo del Gobierno y el Senado y el control de constitucionalidad del TC que ahora reseño.

$$
* * *
$$

TITLE: The tempo moderato of the State's coercive intervention (article 155 SC) in Catalonia: a comment to SSTC 89 and 90/2016, in particular, proportionality and necessity test versus reasonableness of the measures

ABstract: The Constitutional Court has declared under the Constitution the first application of art. 155 CE in Catalonia by means of the Government and Senate agreement of 2017 except to a small extent. This proceeding has been defined as an exceptional mechanism that has to be used with several important restrictions. The whole concrete measures adopted have been considered constitutional. However, the Court warns that cannot apply a test of necessity to this measures but a more external control of reasonableness

Resumen: El TC ha declarado conforme a la Constitución la primera aplicación del art. 155 CE en Cataluña en virtud del Acuerdo del Gobierno y el Senado de 2017 salvo en un pequeño extremo. Ha definido este procedimiento de intervención como un mecanismo excepcional y sometido a diversos límites. Tras revisar las concretas medidas adoptadas, se estiman constitucionalmente adecuadas. Pero se advierte que no debe aplicarse un test de necesidad a la mismas sino un control externo de razonabilidad.

KeY wORDs: State intervention, Coercion, Control over bodies, Parliamentary proceedings, Measures, Control of constitutionality, Necessity test, Proportionality, Reasonableness.

Palabras Clave: Intervención estatal, Coerción, Control sobre los órganos, Procedimiento parlamentario, Medidas, Control de constitucionalidad, Juicio de necesidad, Proporcionalidad, Razonabilidad.

FECHA DE RECEPCIÓN: 02.09.2019

FECHA DE ACEPTACIÓN: 26.09.2019

19 La mayoría secesionista del Parlamento de Cataluña aprobó el 27 de septiembre de 2019, en un Pleno en que varios de sus miembros fueron expulsados del hemiciclo, varias resoluciones que retomaban la senda de la desobediencia civil e institucional, y el Gobierno ha hecho explícita en los medios su voluntad de impugnar estas resoluciones ante el TC y de aplicar más tarde el artículo 155 CE si finalmente concurrieran las circunstancias del supuesto de hecho habilitante. 
